\title{
Experimental study of embedding motion and holding power of drag embedment type anchor on hard and soft seafloor
}

\author{
Hyun-Kyoung Shin ${ }^{1}$, Byoung-Cheon Seo ${ }^{1}$ and Jea-Hoon Lee ${ }^{1}$ \\ ${ }^{1}$ School of Naval Architecture and Ocean Engineering, University of Ulsan, Korea
}

\begin{abstract}
As larger ships and floating offshore structures are, and rougher the marine environment becomes nowadays, a drag embedment type anchor of more stable performance and higher holding power is requested. This paper describes an experimental study of the drag embedding motion and the resultant holding force of three types of drag embedment type anchor model (HALL, AC-14, SEC POOL-N, scale 1/10).
\end{abstract}

KEY WORDS: Drag embedment type anchor (DEA); Embedding motion; Holding power; Embedment depth; Fluke; Failure wedge; Soil heave.

\section{INTRODUCTION}

The basic understanding of the embedding motion and the holding power of drag embedment type anchors (DEA) is necessary to the development of DEA of more stable performance and higher holding power, although the selection of anchoring system depends mostly on the traditional intuitive way of using "Equipment No." table and most recent studies focus only on deep water mooring of floating offshore structures.

This paper describes an experimental study of the embedding motion and the resultant holding force of three types of DEA model. Their relations are analyzed with respect to the anchor geometry and the soil characteristics.
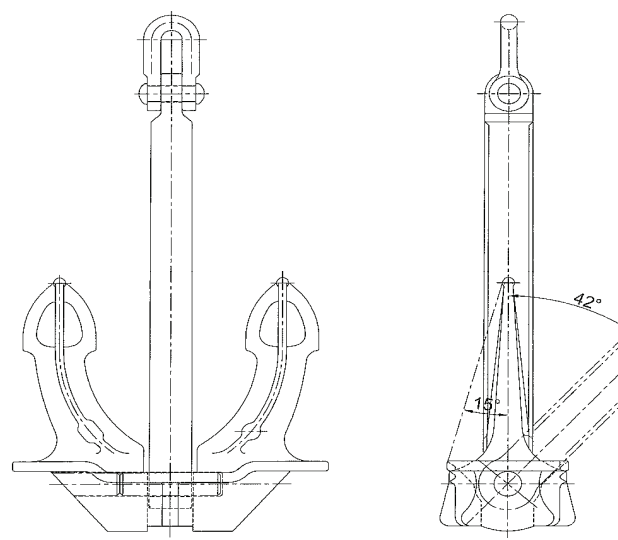

Fig. 1 HALL type (KS, 2006).

Corresponding author: Hyun-Kyoung Shin

e-mail:hkshin@ulsan.ac.kr
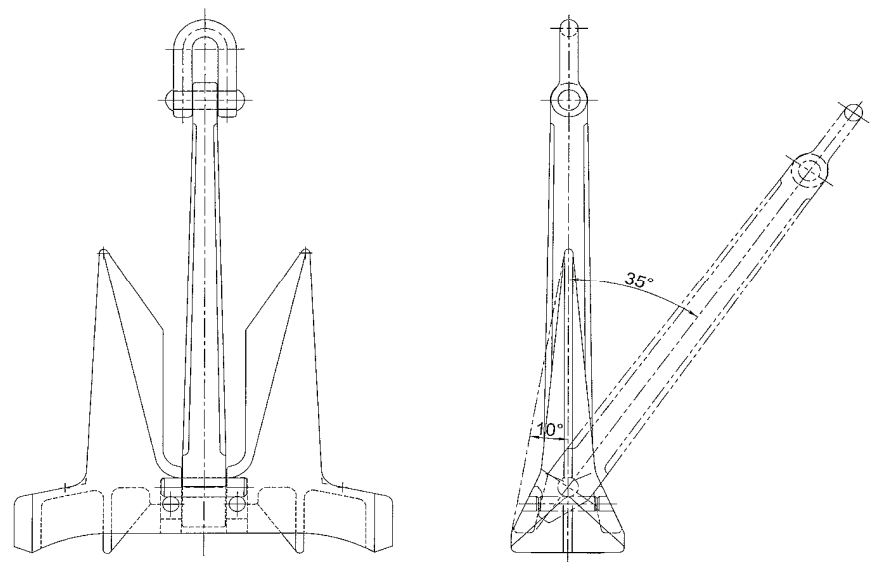

Fig. 2 AC-14 type (H.H.P.) (KS, 2006).
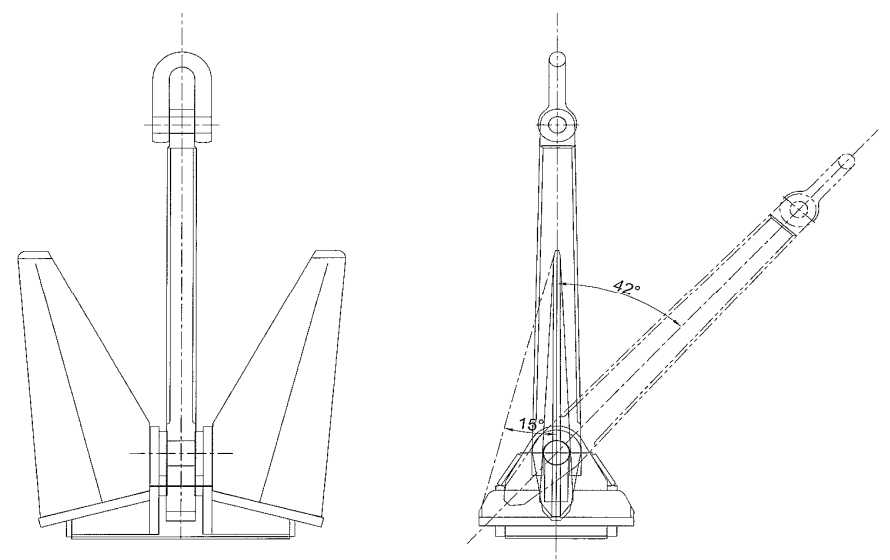

Fig. 3 SEC POOL-N type (H.H.P.) (House, 2002). 


\section{DRAG EMBEDMENT TYPE ANCHOR}

DEA, which is one of effective and widely applied anchors for ships and floating offshore structures including wind turbines, accomplishes the required holding force by its embedding motion, when dragged horizontally.

Three types of DEA (HALL, AC-14, SEC POOL-N, scale 1/10) shown in Figs. 1 3 are generally applied to floating offshore structures and commercial vessels nowadays on both hard and soft seafloor.

\section{DRAG EMBEDMENT TEST}

\section{DEA model}

Eight sets of DEA model are shown in Fig. 4 and Tables 1 2.

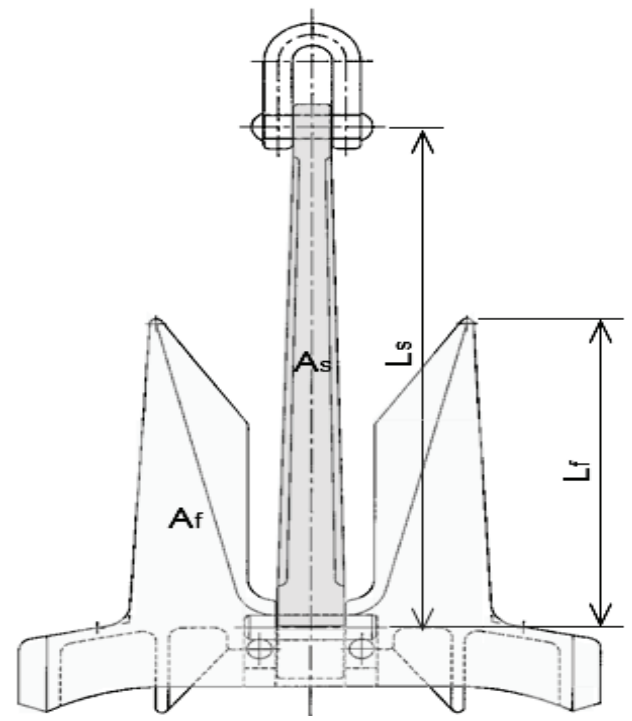

Fig. 4 Anchor geometry and effective area (Lee et al., 2011).

Table 1 Anchor geometry.

\begin{tabular}{|c|c|c|c|c|}
\hline TYPE & $W(\mathrm{~kg})$ & $W a(\mathrm{~kg})$ & $L s(\mathrm{~mm})$ & $L f(\mathrm{~mm})$ \\
\hline \multirow{3}{*}{$\begin{array}{c}\text { HALL } \\
\left(\theta 1=42^{\circ}\right)\end{array}$} & 6000 & 7.36 & 293 & 154 \\
\cline { 2 - 5 } & 9350 & 10.68 & 339 & 175 \\
\cline { 2 - 5 } & 12300 & 13.38 & 175 & 196 \\
\hline \multirow{2}{*}{$\begin{array}{c}\text { AC-14 } \\
\left(\theta 1=35^{\circ}\right)\end{array}$} & 4500 & 5.74 & 264 & 163 \\
\cline { 2 - 5 } & 6975 & 8.62 & 305 & 188 \\
\hline \multirow{2}{*}{$\begin{array}{c}\text { POOL-N } \\
\left(\theta 1=42^{\circ}\right)\end{array}$} & 9225 & 11.30 & 333 & 206 \\
\cline { 2 - 5 } & 9225 & 8.84 & 310 & 192 \\
\hline
\end{tabular}

$W:$ Weight of anchor (class)

$W a:$ Weight of model anchor

Ls : Length of shank

$S f$ : Length of fluke
Table 2 Effective area.

\begin{tabular}{|c|c|c|c|}
\hline TYPE & $W(\mathrm{kgf})$ & $A s\left(\mathrm{~mm}^{2}\right)$ & $A f\left(\mathrm{~mm}^{2}\right)$ \\
\hline \multirow{3}{*}{ HALL } & 6000 & 8058 & 10010 \\
\cline { 2 - 4 } & 9350 & 12770 & 13852 \\
\cline { 2 - 4 } & 12300 & 13485 & 16148 \\
\hline \multirow{3}{*}{ AC-14 } & 4500 & 5619 & 21802 \\
\cline { 2 - 4 } & 6975 & 7503 & 28320 \\
\cline { 2 - 4 } & 9225 & 10196 & 34502 \\
\hline \multirow{3}{*}{ POOL-N } & 6975 & 6541 & 29836 \\
\cline { 2 - 4 } & 9225 & 7748 & 35744 \\
\hline
\end{tabular}

As : Area of shank

Af: Area of fluke

\section{Model test}

The drag embedment model test is carried out in the test tank $(\mathrm{L} \times \mathrm{B} \times \mathrm{H}=4000 \times 900 \times 900 \mathrm{~mm})$ shown in Fig. 5 with both hard (sand) and soft (mud) seafloor. Also, anchor embedment depths and holding forces are measured by the ruler and the load cell, respectively, located on wire between the winch and the upper sheave.

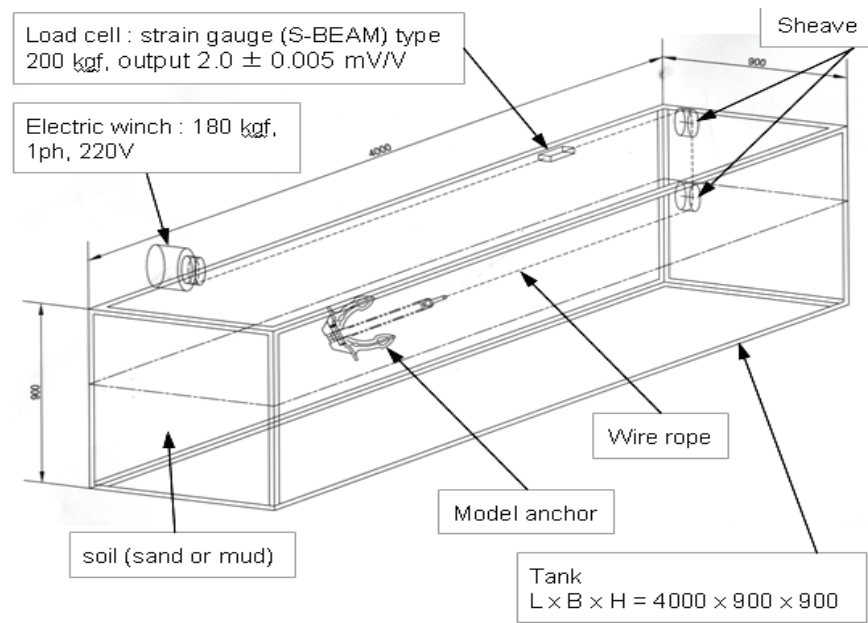

Fig. 5 Test tank.

Tank : $\mathrm{L} \times \mathrm{B} \times \mathrm{H}(\mathrm{mm})=4000 \times 900 \times 900$

- Load cell : strain gauge (S-BEAM) type, $200 \mathrm{kgf}$, output $2.0 \pm 0.005 \mathrm{mV} / \mathrm{V}$

\section{Test result}

\section{Holding force and displacement}

The measured anchor holding force $\mathrm{F}$ to the dragged distance of each type of anchors on sand and mud seafloor can be graphically shown. (Figs. 6 19)

$\mathrm{X}$-axis : dragged distance of anchors $(m), l$

Y-axis : holding force $(\mathrm{kgf}), \mathrm{F}$ 


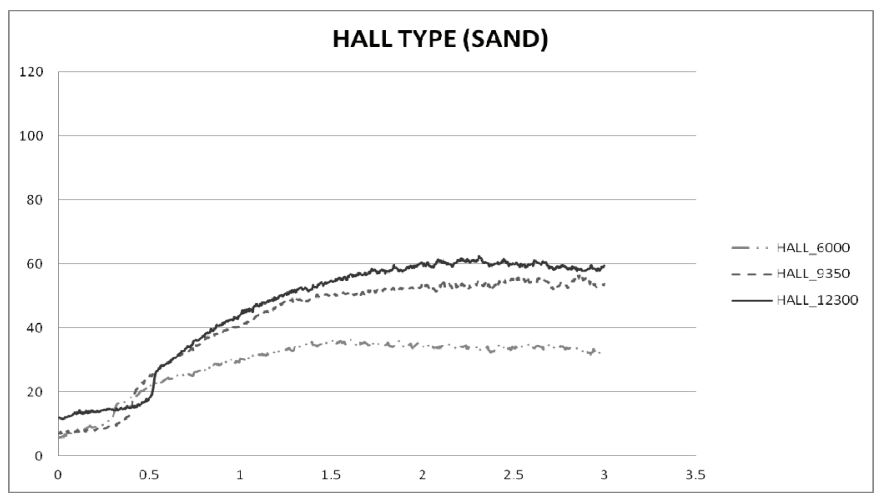

Fig. 6 HALL type (sand).

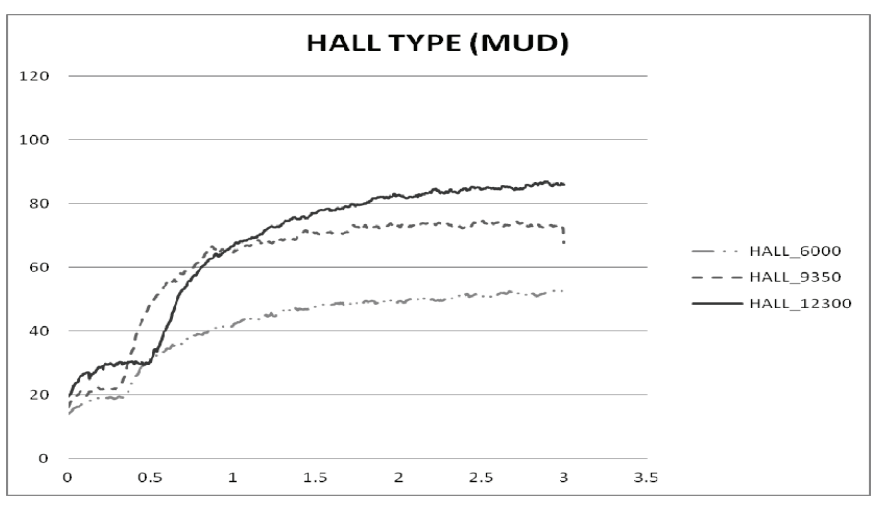

Fig. 7 HALL type (mud).

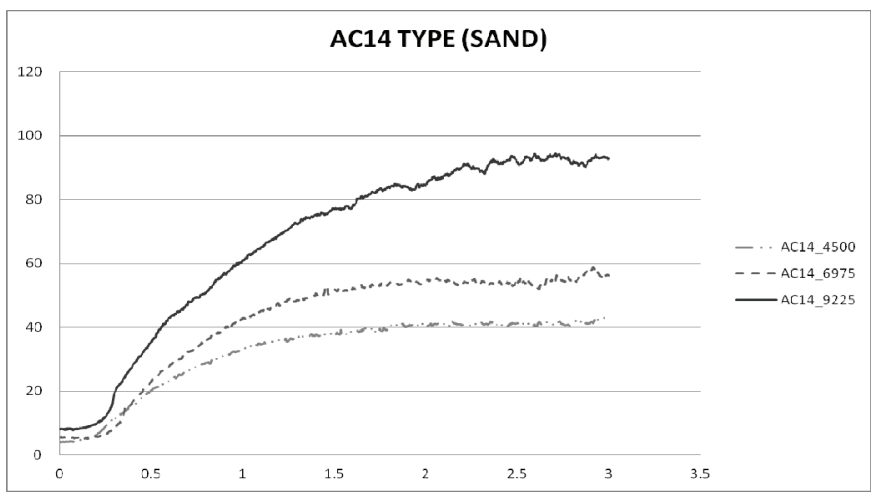

Fig. 8 AC-14 type (sand).

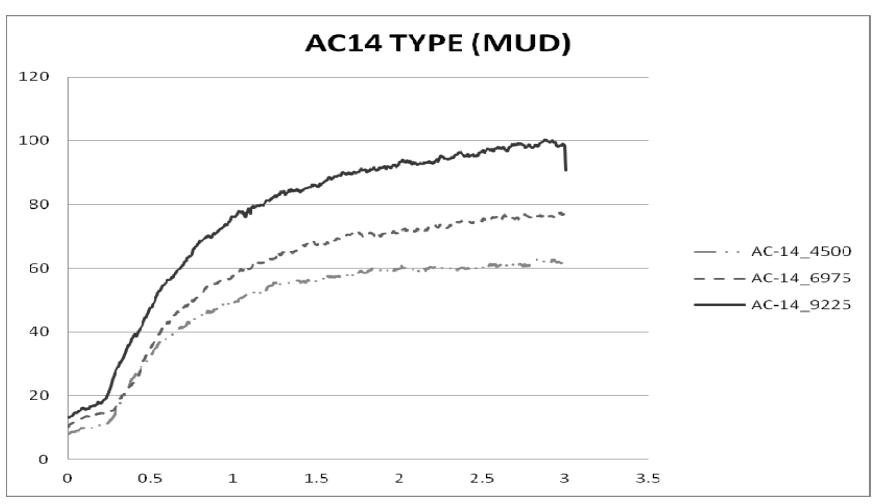

Fig. 9 AC-14 type (mud).

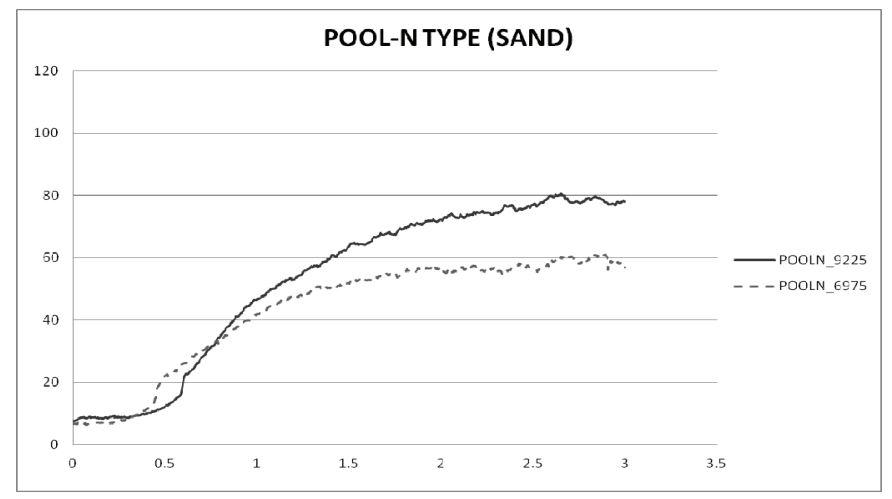

Fig. 10 POOL-N type (sand).

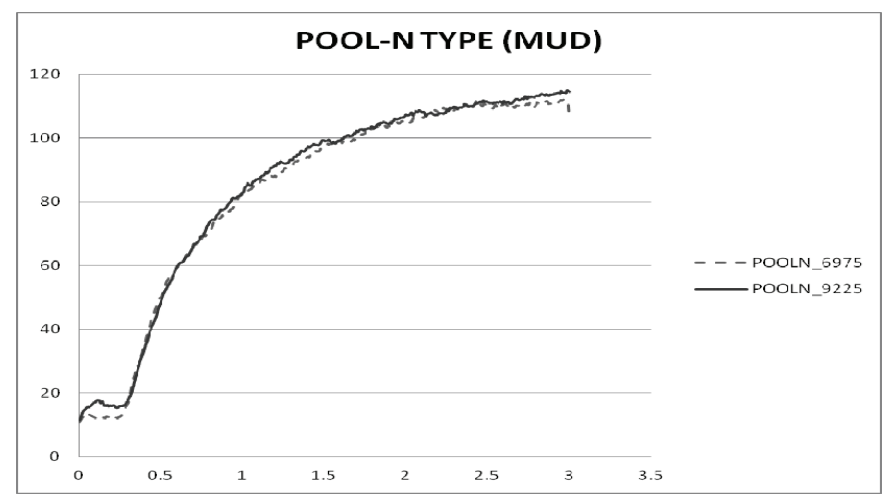

Fig. 11 POOL-N type (mud).

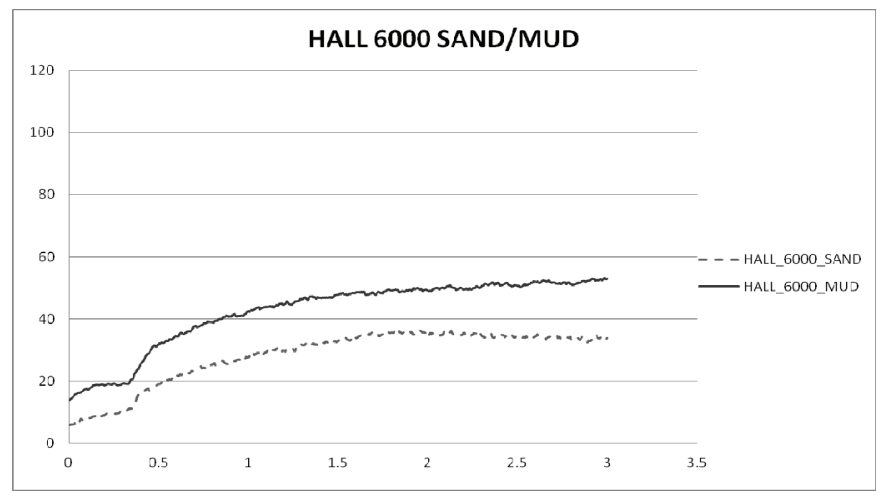

Fig. 12 HALL type, $6000 \mathrm{kgf}$.

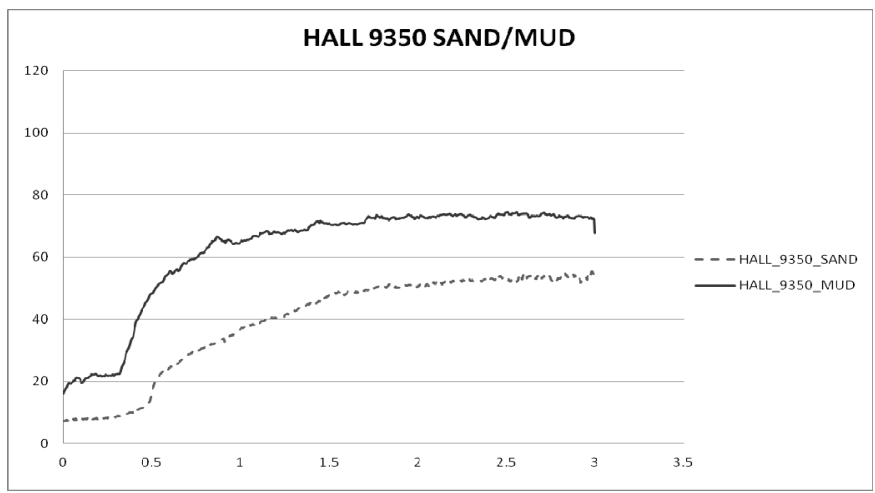

Fig. 13 HALL type, $9350 \mathrm{kgf}$. 


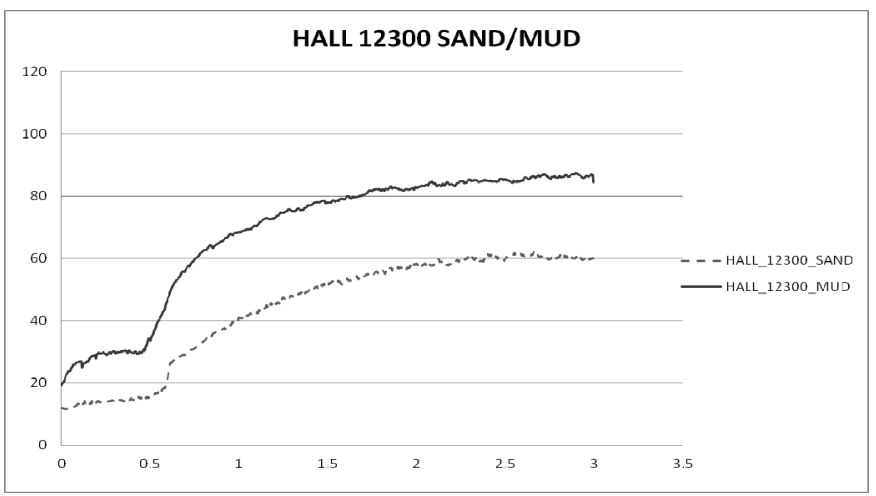

Fig. 14 HALL type, $12300 \mathrm{kgf}$.

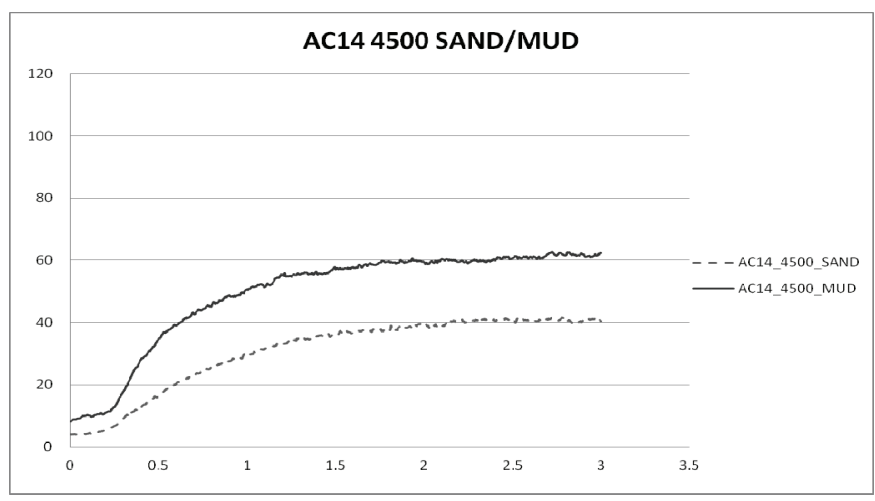

Fig. 15 AC-14 type, $4500 \mathrm{kgf}$.

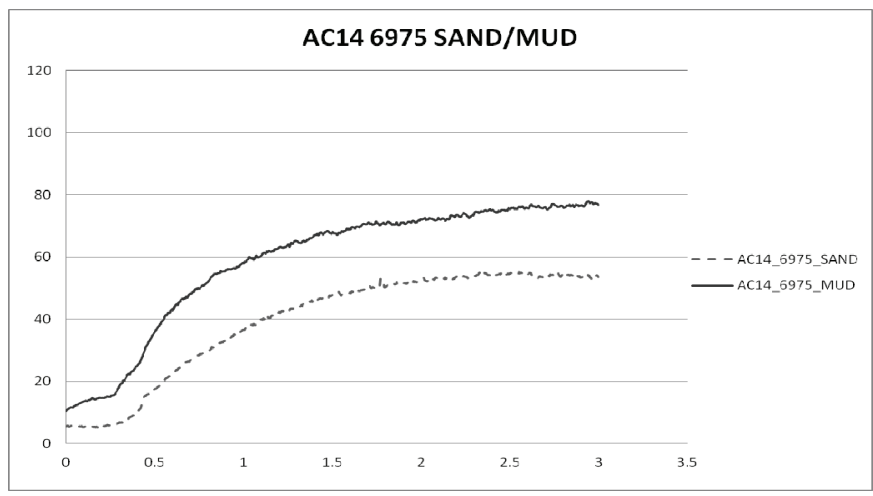

Fig. 16 AC-14 type, $6975 \mathrm{kgf}$.

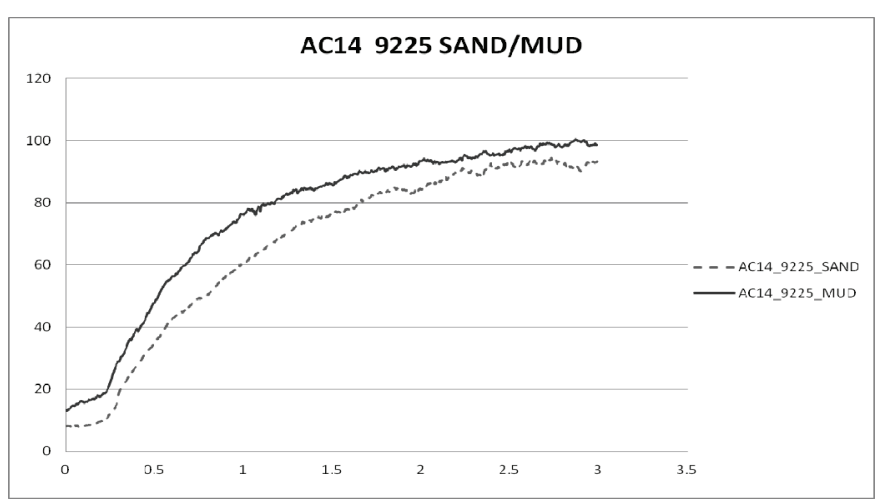

Fig. 17 AC-14 type, 9225 kgf.

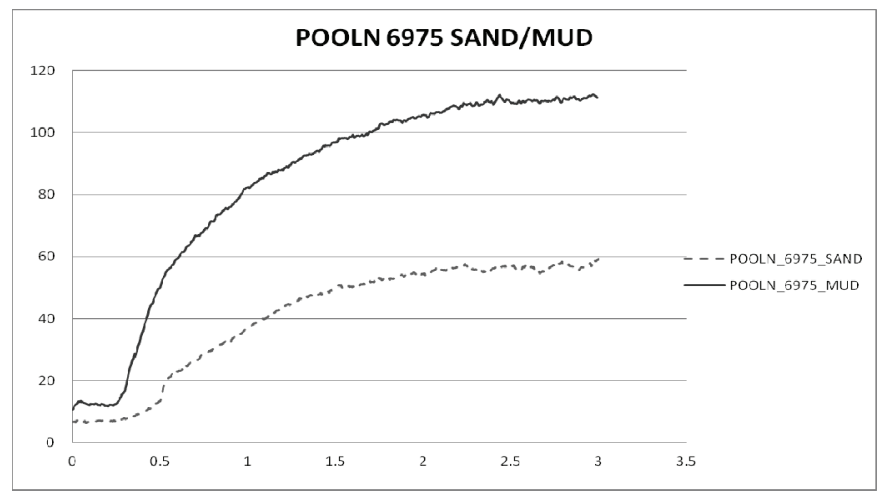

Fig. 18 POOL-N type, 6975 kgf.

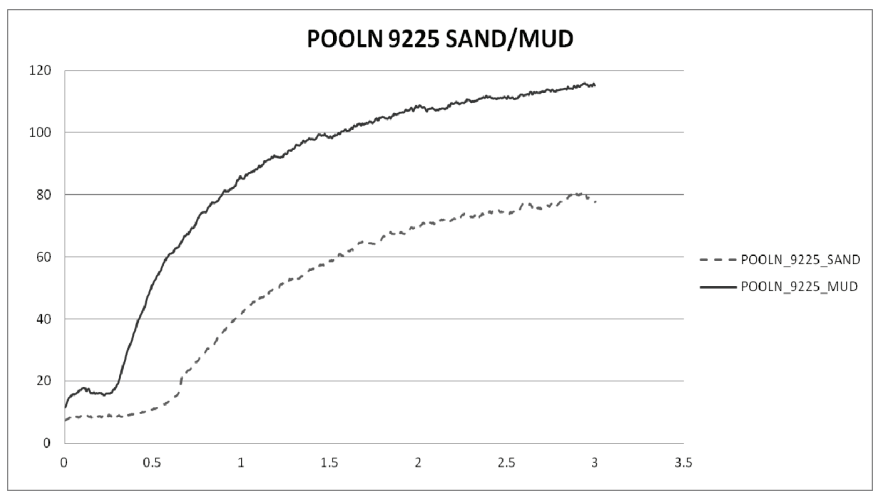

Fig. 19 POOL-N type, $9225 \mathrm{~kg}$.

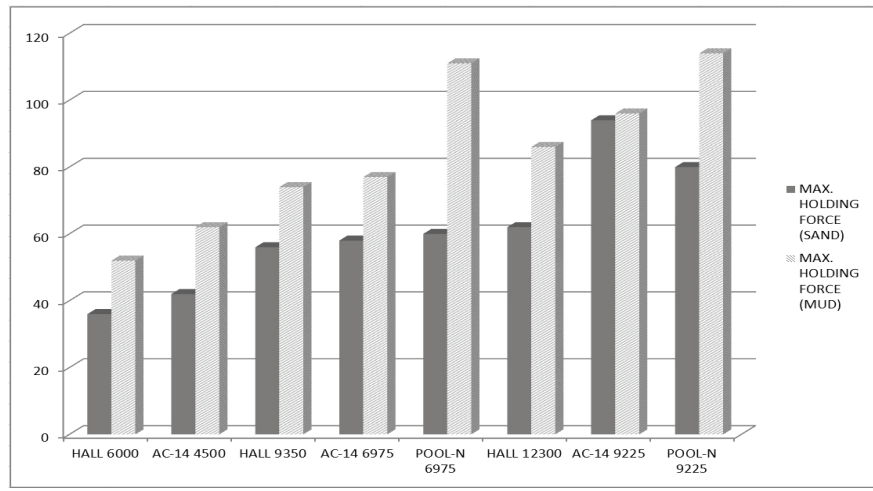

Fig. 20 Max. holding force of model anchors.

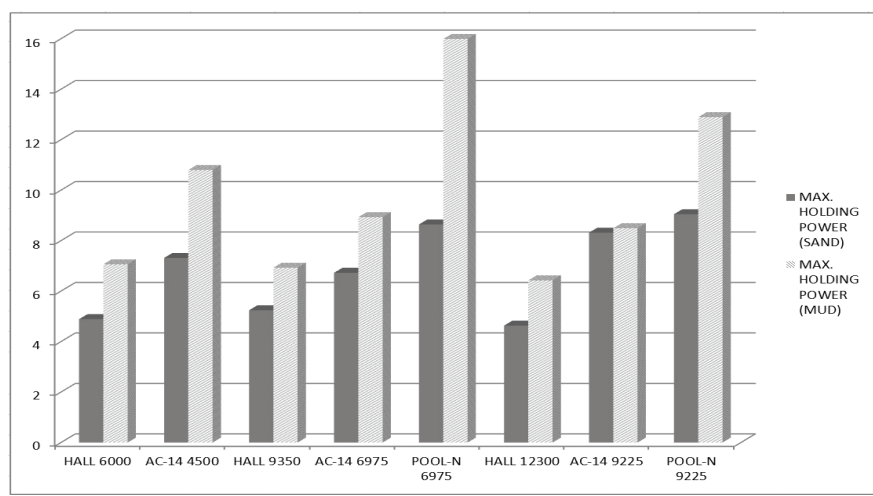

Fig. 21 Max. holding power of model anchors. 
As shown in Figs. 6 19, the holding force $F$ increases steeply after initial penetration stage of model anchors and finally converges to its max. holding force. The holding force and the embedment depth on mud soil are higher than those on sand soil, respectively. It holds in all three types of anchor.

Also, Fig. 20 shows that the max. holding force of bigger model anchors is higher than that of the smaller ones of the same model.

The anchor embedding capability can be represented by the max. holding power, which is defined as the ratio of the max. holding force to its weight on Y-axis.

As shown in Fig. 21, the max. holding powers measured at the model test differ from each other in different types of anchor and soil.

\section{Comparison with NCEL's anchor holding capacity}

The anchor holding capacities from the model tests are plotted on the graphs prepared by NCEL in Fig. 22, and compared with each other to accredit them.

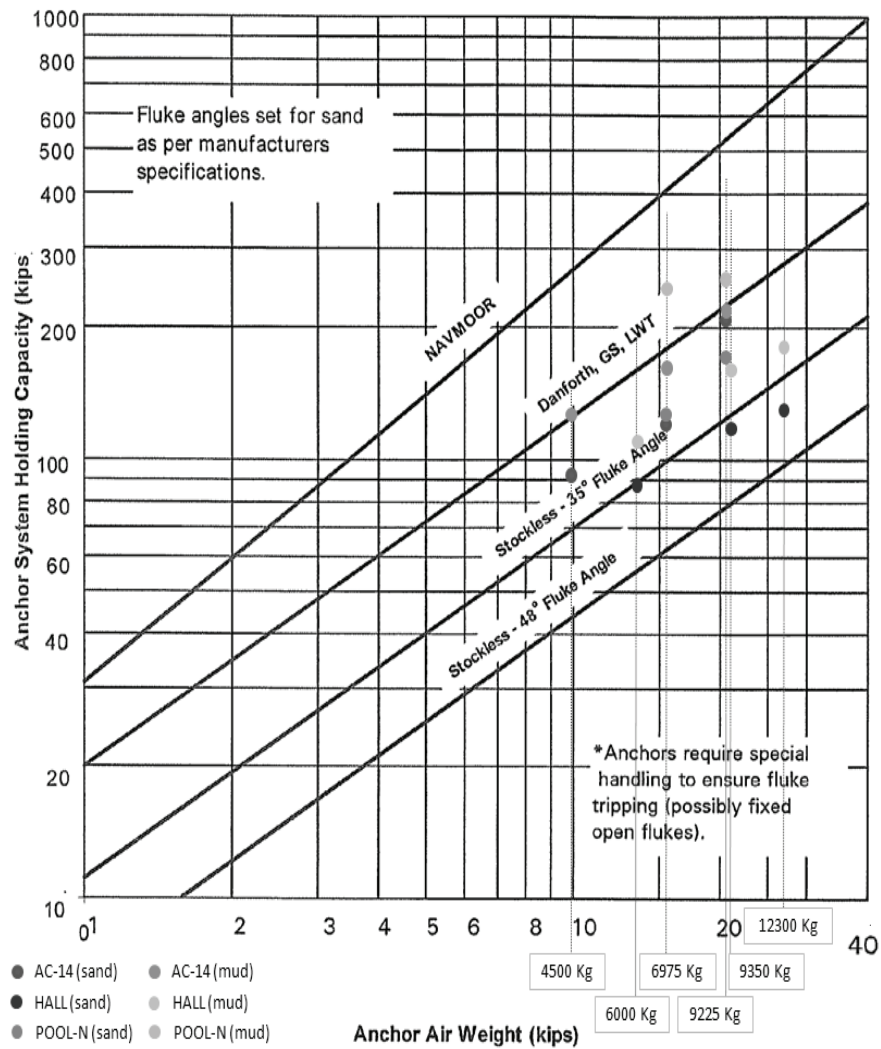

Fig. 22 Comparison with NCEL's anchor holding capacity (NCEL 1987).

\section{Anchor embedment depth}

In order to verify the relation between the holding capacity and the embedment motion of each anchor, final depths of the anchor pin and the fluke tip are measured after each test of anchors on both sand and mud seafloor, of which mean values are described in Tables 3 4.
Table 3 Anchor embedment depth (sand).

\begin{tabular}{|c|c|c|c|}
\hline TYPE & $W(\mathrm{~kg} f)$ & $D s(\mathrm{~mm})$ & $D f(\mathrm{~mm})$ \\
\hline \multirow{3}{*}{ HALL } & 6000 & 0 & 144 \\
\cline { 2 - 4 } & 9350 & 0 & 164 \\
\cline { 2 - 4 } & 12300 & 0 & 183 \\
\hline \multirow{3}{*}{ AC-14 } & 4500 & 0 & 157 \\
\cline { 2 - 4 } & 6975 & 0 & 182 \\
\cline { 2 - 4 } & 9225 & 0 & 199 \\
\hline \multirow{2}{*}{ POOL-N } & 6975 & 0 & 177 \\
\cline { 2 - 4 } & 9225 & 0 & 193 \\
\hline
\end{tabular}

$D s$ : Depth of anchor pin

$D f$ : Depth of fluke tip

Table 4 Anchor embedment depth (mud).

\begin{tabular}{|c|c|c|c|}
\hline TYPE & $W(\mathrm{kgf})$ & $D s(\mathrm{~mm})$ & $D f(\mathrm{~mm})$ \\
\hline \multirow{3}{*}{ HALL } & 6000 & 57 & 173 \\
\cline { 2 - 4 } & 9350 & 83 & 240 \\
\cline { 2 - 4 } & 12300 & 80 & 250 \\
\hline \multirow{3}{*}{ AC-14 } & 4500 & 130 & 260 \\
\cline { 2 - 4 } & 6975 & 140 & 373 \\
\cline { 2 - 4 } & 9225 & 113 & 230 \\
\hline \multirow{2}{*}{ POOL-N } & 6975 & 168 & 328 \\
\cline { 2 - 4 } & 9225 & 170 & 327 \\
\hline
\end{tabular}

\section{Soil characteristic}

The particle size distribution of sand and mud used in the test, was obtained by the sieve analysis according to KS F2309 (Figs. 23 24) and the hydrometer analysis according to KS F2302-92 was additionally made for mud's very small particles (Fig. 25).

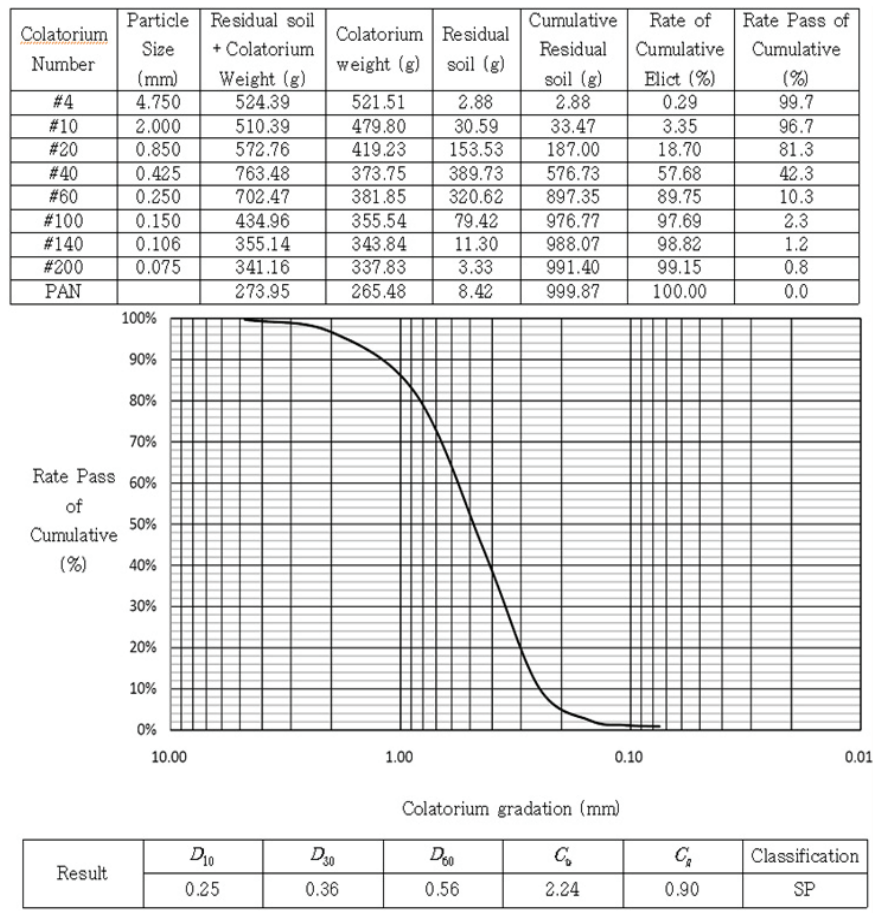

Fig. 23 Particle size distribution (sand). 


\begin{tabular}{|c|c|c|c|c|c|c|c|}
\hline $\begin{array}{c}\text { Colatorium } \\
\text { Number }\end{array}$ & $\begin{array}{c}\text { Particle } \\
\text { Size } \\
(\mathrm{mm})\end{array}$ & $\begin{array}{c}\text { Residual soil } \\
+ \text { Colatorium } \\
\text { Weight }(\mathrm{g})\end{array}$ & $\begin{array}{c}\text { Colatorium } \\
\text { weight }(\mathrm{g})\end{array}$ & $\begin{array}{c}\text { Residual } \\
\text { soil }(\mathrm{g})\end{array}$ & $\begin{array}{c}\text { Cumulative } \\
\text { Residual } \\
\text { soil }(\mathrm{g})\end{array}$ & $\begin{array}{c}\text { Rate of } \\
\text { Cumulative } \\
\text { Elict }(\%)\end{array}$ & $\begin{array}{c}\text { Rate Pass of } \\
\text { Cumulative } \\
(\%)\end{array}$ \\
\hline$\# 4$ & 4.750 & 536.85 & 521.92 & 14.93 & 14.93 & 1.50 & 98.5 \\
\hline$\# 10$ & 2.000 & 597.28 & 480.05 & 117.23 & 132.16 & 13.29 & 86.7 \\
\hline$\# 20$ & 0.850 & 612.42 & 418.61 & 193.81 & 325.97 & 32.78 & 67.2 \\
\hline$\# 40$ & 0.425 & 512.94 & 373.32 & 139.62 & 465.59 & 46.82 & 53.2 \\
\hline$\# 60$ & 0.250 & 490.69 & 381.77 & 108.92 & 574.51 & 57.77 & 42.2 \\
\hline$\# 100$ & 0.150 & 453.28 & 355.55 & 97.73 & 672.24 & 67.60 & 32.4 \\
\hline$\# 140$ & 0.106 & 391.76 & 348.83 & 42.93 & 715.17 & 71.91 & 28.1 \\
\hline$\# 200$ & 0.075 & 375.06 & 337.83 & 37.23 & 752.40 & 75.66 & 24.3 \\
\hline PAN & & 465.87 & 223.80 & 242.07 & 994.47 & 100.00 & 0.0 \\
\hline
\end{tabular}

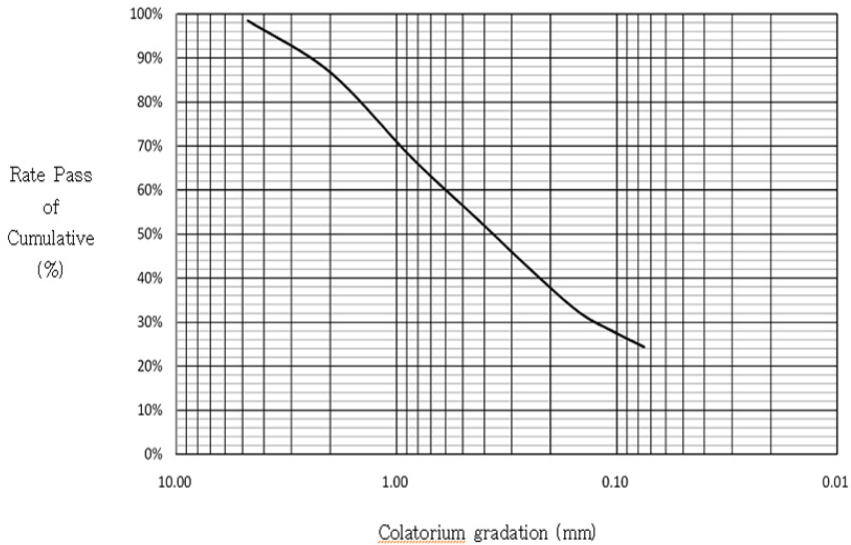

Colatorium gradation $(\mathrm{mm})$

\begin{tabular}{|c|c|c|c|c|c|c|}
\hline \multirow{2}{*}{ Result } & $D_{10}$ & $D_{30}$ & $D_{60}$ & $C_{\mathrm{b}}$ & $C_{\mathrm{Q}}$ & Classification \\
\cline { 2 - 7 } & 0.00056 & 0.13 & 0.60 & 1071.43 & 50.30 & $\mathrm{SC}$ \\
\hline
\end{tabular}

Fig. 24 Particle size distribution (mud).

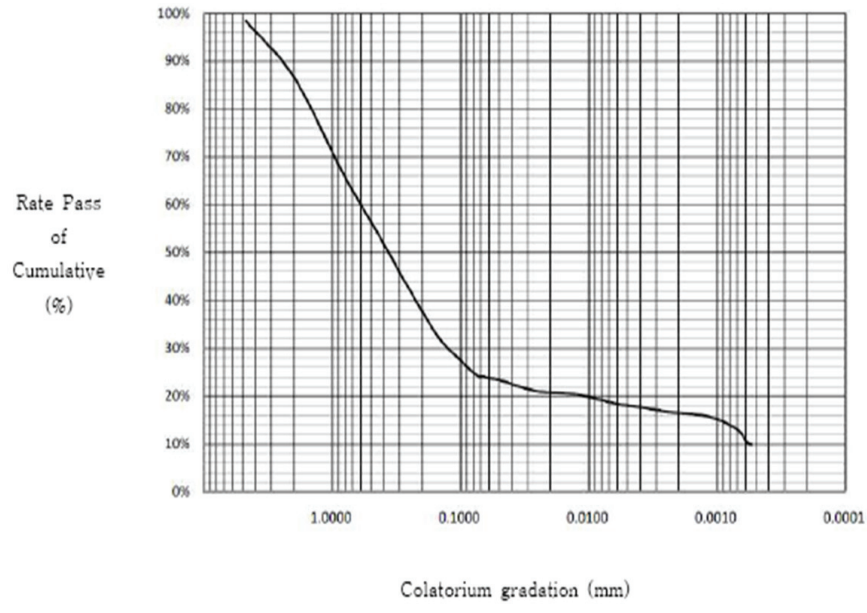

Fig. 25 Particle size distribution (mud).

As shown in Fig. 23, the soil used in the sand test consists most of sand (around 96\%), according to USCS (Unified Soil Classification System).

Particle size - clay : $\sim 0.005 \mathrm{~mm}$,

silt : $0.005 \sim 0.07 \mathrm{~mm}$,

sand : $0.07 \sim 2 \mathrm{~mm}$,

gravel : $2 \mathrm{~mm} \sim$

The soil used on the mud test consists of clay (25\%), sand $(60 \%)$, and gravel (15\%), as shown in Figs. 24 25.

The wet density of each soil is measured as below. Density $(\rho): 1779 \mathrm{~kg} / \mathrm{m}^{3}$ (sand), $1942 \mathrm{~kg} / \mathrm{m}^{3}$ (mud).

\section{ANCHOR EMBEDMENT MOTION}

The embedment motion can be diversified by three (3) stages as in Figs. 26 27. (Lee et al., 2011)

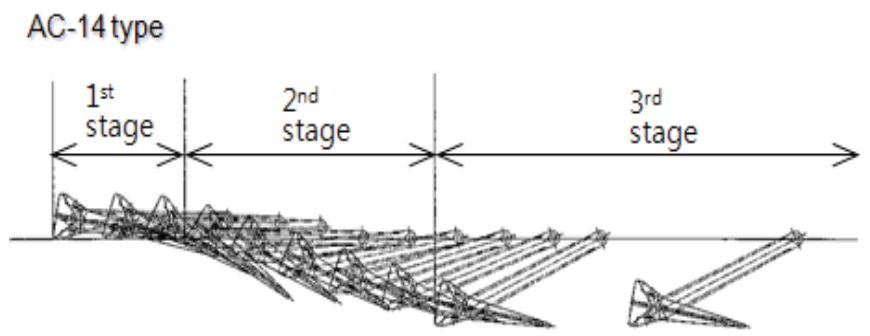

POOL N type

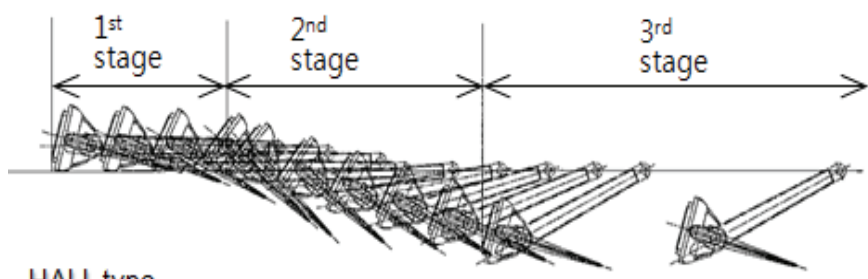

HALL type

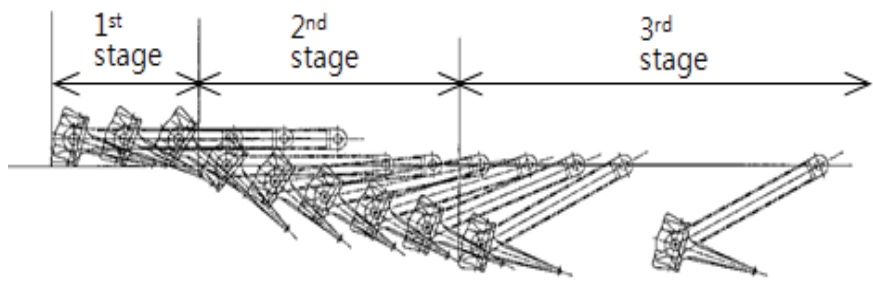

Fig. 26 Anchor embedment motion.

\section{Simplified model}

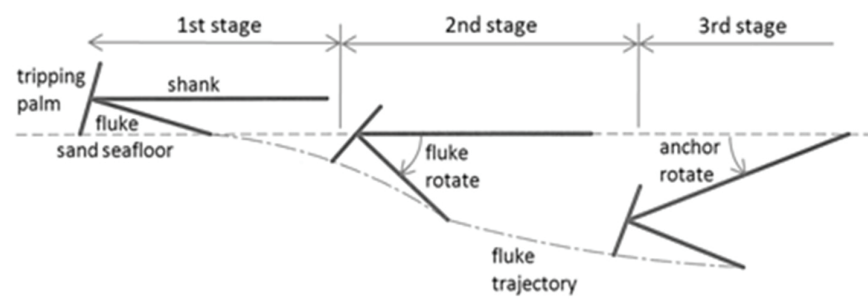

Fig. 27 Simplified anchor embedment motion.

$1^{\text {st }}$ stage : At the first stage of anchor being dragged, anchor fluke tends to rotate and to be embedded into soil by soil resistance on the tripping palm and weight of soil accumulated over the fluke.

$2^{\text {nd }}$ stage : As the anchor fluke rotates with embedment to its max. angle $\left(35^{\circ}\right.$ for $\mathrm{AC}-14,42^{\circ}$ for HALL and POOL-N), the anchor shank is going to rotate and to be embedded to the force equilibrium state.

$3^{\text {rd }}$ stage : After the force equilibrium of anchor drag force to soil resistance is established, the anchor is dragged without further embedment, and the max. holding force of DEA is acquired at this stage. 


\section{ANCHOR HOLDING FORCE}

Conventional marine anchor are characterized by

a. Shallow embedment due to large shank width

b. Development of soil heave due to large fluke wedge angle

c. Bi-directionally embedment due to fluke rotation

d. Holding force depends on the weight of anchor

$\mathrm{F}=\mathrm{W} \cdot \mathrm{N}$

$\mathrm{W}:$ Weight of anchor

$\mathrm{N}$ : Bearing capacity factor

Newly developed offshore anchor are characterized by

a. Deep embedment due to small shank width (plated dual shank)

b. No development of soil heave due to small fluke wedge angle (corrugated plate fluke)

c. One directional embedment due to fixed fluke

d. Holding force depending on the soil weight of failure wedge in Fig. 28. (Neubecker and Randolph, 1996 b)

$\mathrm{F}=\mathrm{A} \cdot \rho \mathrm{g} \cdot \mathrm{d} \cdot \mathrm{N}$

$\rho:$ Density of wet soil

$g:$ Acceleration of gravity

$d$ : Depth of fluke

$N$ : Bearing capacity factor

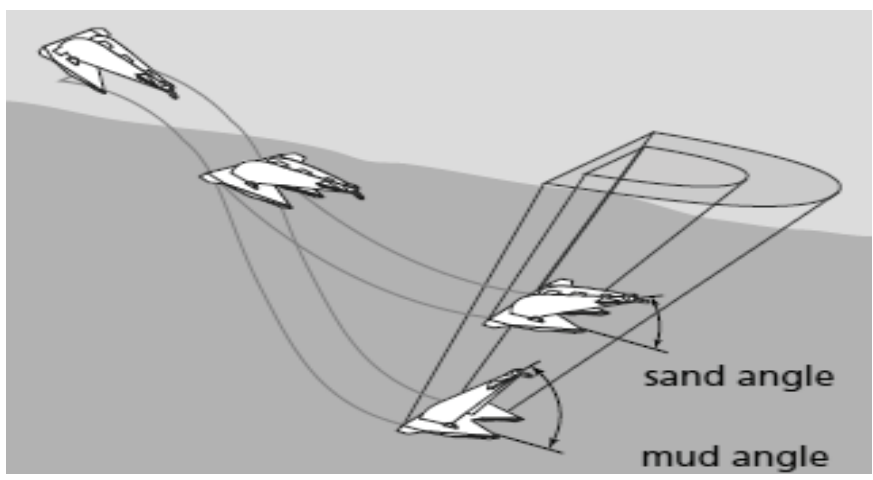

Fig. 28 Failure wedge (Vryhof, 2010).

Development of soil heave in Fig. 29 affects the soil weight of failure wedge (Neubecker and Randolph, 1996 a).

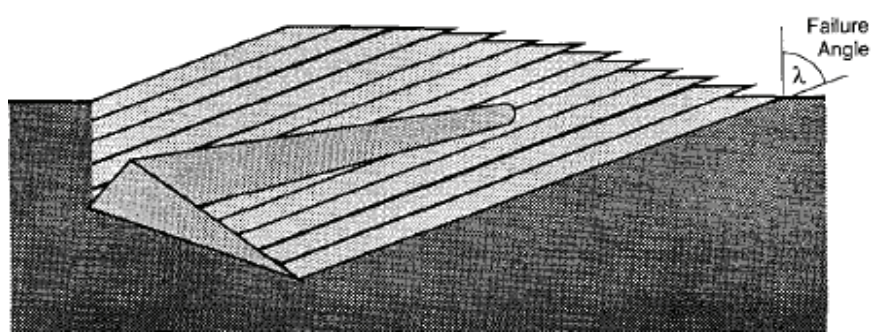

Fig. 29 Development of soil heave.
Based on the test results, the anchor holding force can be diversified by that in each stage (Fig. 30)

F1 : Initial drag force

F2 : Final drag force of stage 1 and initial drag force of stage 2

F3 : Final drag force of stage 2 (max. holding force)

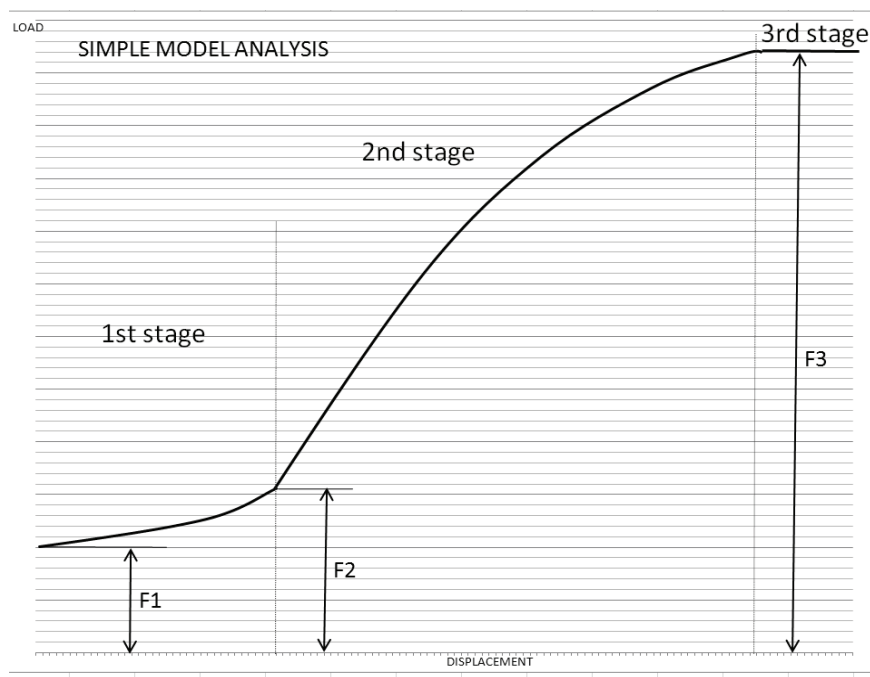

Fig. 30 Simplified curve of drag force.

Table 5 Drag force of each stage (sand).

\begin{tabular}{|c|c|c|c|c|}
\hline TYPE & $W(\mathrm{~kg} f)$ & $\mathrm{F} 1(\mathrm{~kg} f)$ & $\mathrm{F} 2$ & $\mathrm{~F} 3$ \\
\hline \multirow{3}{*}{ HALL } & 6000 & 6 & 11 & 36 \\
\cline { 2 - 5 } & 9350 & 8 & 13 & 56 \\
\cline { 2 - 5 } & 12300 & 12 & 19 & 62 \\
\hline \multirow{3}{*}{ AC-14 } & 4500 & 4 & 6 & 42 \\
\cline { 2 - 5 } & 6975 & 6 & 10 & 58 \\
\cline { 2 - 5 } & 9225 & 8 & 14 & 94 \\
\hline \multirow{2}{*}{ POOL-N } & 6975 & 7 & 13 & 60 \\
\cline { 2 - 5 } & 9225 & 8 & 16 & 80 \\
\hline
\end{tabular}

Table 6 Drag force of each stage (mud).

\begin{tabular}{|c|c|c|c|c|}
\hline TYPE & $W(k g f)$ & $\mathrm{F} 1(\mathrm{~kg} f)$ & $\mathrm{F} 2$ & $\mathrm{~F} 3$ \\
\hline \multirow{3}{*}{ HALL } & 6000 & 14 & 19 & 52 \\
\cline { 2 - 5 } & 9350 & 16 & 22 & 74 \\
\cline { 2 - 5 } & 12300 & 19 & 30 & 86 \\
\hline \multirow{3}{*}{ AC-14 } & 4500 & 8 & 12 & 62 \\
\cline { 2 - 5 } & 6975 & 10 & 15 & 77 \\
\cline { 2 - 5 } & 9225 & 13 & 20 & 96 \\
\hline \multirow{2}{*}{ POOL-N } & 6975 & 10 & 12 & 111 \\
\cline { 2 - 5 } & 9225 & 12 & 16 & 114 \\
\hline
\end{tabular}

The drag force in each stage can be differently derived as below.

In the 1st stage, most of drag forces are caused by friction between anchor and soil and the equation (1) can be used as a drag force equation. 
$F 1, F 2=N 1 \cdot(W+C \cdot$ Wadd $)$

$N 1$ : Bearing capacity factor of stage 1

$W$ : Weight of anchor

Wadd : Weight of sand accumulated over the fluke

$($ Wadd $=(A f \cdot L f \cdot \rho g \cdot \sin \theta 1) / 2)$

$C$ : calibrating constant, including soil heave effect

$\gamma:$ Specific weight of wet soil $(\gamma=\rho g)$

On the $2^{\text {nd }}$ stage, most of drag forces are caused by soil resistance on the failure wedge surface and the equation (2) can be used as a drag force equation.

\section{$F 3=F 2+N 2 \cdot A f \cdot \rho g \cdot d$}

$N 2$ : Bearing capacity factor of stage 2

$A$ : Fluke area

$d$ : Depth of fluke

By applying the test results to Eqs. (3) and (4), bearing capacity factors of each stage are derived as in Tables 7 8.

Table 7 Bearing capacity factor (sand).

\begin{tabular}{|c|c|c|c|c|}
\hline TYPE & $W(\mathrm{kgf})$ & N1 & C & N2 \\
\hline \multirow{3}{*}{ HALL } & 6000 & $0.79-0.82$ & \multirow{3}{*}{1.2} & 9.75 \\
\hline & 9350 & $0.71-0.75$ & & 10.60 \\
\hline & 12300 & $0.90-0.96$ & & 8.18 \\
\hline \multirow{3}{*}{ AC-14 } & 4500 & 0.70 & \multirow{3}{*}{1.6} & 5.91 \\
\hline & 6975 & 0.70 & & 5.23 \\
\hline & 9225 & 0.71 & & 6.55 \\
\hline \multirow{2}{*}{ POOL-N } & 6975 & $1.01-1.05$ & \multirow{2}{*}{1.8} & 5.00 \\
\hline & 9225 & $0.90-0.93$ & & 5.21 \\
\hline
\end{tabular}

Table 8 Bearing capacity factor (mud).

\begin{tabular}{|c|c|c|c|c|}
\hline TYPE & $W(k g f)$ & N1 & C & $N 2$ \\
\hline \multirow{3}{*}{ HALL } & 6000 & $1.81-1.90$ & \multirow{3}{*}{1.2} & 11.80 \\
\hline & 9350 & $1.40-1.50$ & & 11.80 \\
\hline & 12300 & $1.42-1.50$ & & 9.76 \\
\hline \multirow{3}{*}{ AC-14 } & 4500 & $1.35-1.39$ & \multirow{3}{*}{1.6} & 7.52 \\
\hline & 6975 & $1.12-1.16$ & & 6.19 \\
\hline & 9225 & $1.11-1.15$ & & 5.70 \\
\hline \multirow{2}{*}{ POOL-N } & 6975 & $1.44-1.45$ & \multirow{2}{*}{1.8} & 9.65 \\
\hline & 9225 & $1.35-1.36$ & & 7.32 \\
\hline
\end{tabular}

\section{CONCLUSIONS}

This study is carried out to verify the drag embedding motion and the resultant holding force of three types of anchor models (HALL, AC-14, POOL-N) on both hard(mud) and soft(sand) seafloor, and to derive governing equations, regarding the relations of the anchor geometry and the holding force.

Considering the test results, the anchor embedding motion is diversified by three stages with different kinds of motion and force applied and, finally, the governing drag force equation in each stage is derived with respect to the anchor geometry and the embedded depth on both hard and soft seafloor, using the bearing capacity factor.

The results can be used to verify the actual holding capacity of each type of DEA, as reference, and be used as fundamental data for the development of more efficient and higher performance DEA in the future.

\section{ACKNOWLEDGEMENT}

This work was supported by the Human Resources Development of the Korea Institute of Energy Technology Evaluation and Planning (KETEP) grant funded by the Korea government Ministry of Knowledge Economy. (No. 20114030200050 )

\section{REFERENCES}

House, D.J., 2002. Anchor Practice. 1st Ed. Witherby. KS V 3311, 2006. Anchor. Korean Standards Association.

Lee, J.H. Seo, B.C. and Shin, H., 2011. Experimental Study of Embedding Motion and Holding Power of Drag Embedment Type Anchor on Sand Seafloor. Journal of the Society of Naval Architects of Korea, 48(2), pp.183-187.

Naval Civil Engineering Laboratory (NCEL), 1987. Drag embedment anchors for navy moorings.

Neubecker, S.R. and Randolph, M.F., 1996a. The Kinematic Behavior of Drag Anchors in Sand. Can. Geotech. J. 33, pp.574-583.

Neubecker, S.R. and Randolph, M.F., 1996b. The Static Equilibrium of Drag Anchors in Sand. Can. Geotech. J. 33, pp.584-594.

Vryhof Anchors B.V., 2010. Anchor manual 2010 [online] (Updated 2006) Available at : http://www.vryhof.com [Accessed 24 September 2011]. 